\title{
INNOVATION AND TECHNOLOGICAL APPLICATIONS IN THE BANKING AND FINANCIAL SERVICES: TURKIYE IS BANKASI CASE
}

\author{
DOI: 10.17261/Pressacademia.2019.1096 \\ PAP- V.9-2019(43)-p.226-230
}

\section{Demokaan Demirel ${ }^{1}$, Vedat Eris ${ }^{2}$}

${ }^{1}$ Kocaeli University, Faculty of Economics and Administrative Sciences, Kocaeli, Turkey demokaan.demirel@kocaeli.edu.tr, ORCID: 0000-0001-5454-9507

2Kocaeli University, Faculty of Economics and Administrative Sciences, Kocaeli, Turkey eris vedat@hotmail.com,ORCID: 0000-0002-8196-9504

To cite this document

Demirel, D., Eris, V., (2019). Innovation and technological applications in the banking and financial services: Turkiye Is Bankası case. PressAcademia Procedia (PAP), V.9, p.226-230

Permemant link to this document: http://doi.org/10.17261/Pressacademia.2019.1096

Copyright: Published by PressAcademia and limited licenced re-use rights only.

\section{ABSTRACT}

Purpose- As a result of the studies conducted in the market, various tools have emerged. For example, in the banking sector, many products such as debit cards, credit cards, internet branch, mobile banking, diversified credit facilities, forward transactions have tried to find a place in the market. With the innovative and technological applications, the main purpose is to facilitate access to information, to reduce cost and to increase customer satisfaction. Türkiye İş Bankası has been one of the institutions trying to make a difference in its sector with its efforts in the modern world. In this study, innovative and technological studies in banking and finance sector have been examined recently and the application of the science and communication technologies of Türkiye Iş Bankası in the sector will be discussed.

Methodology- The study is based on the review of innovative practices in the banking sector through the case of Türkiye iş Bankası. Evaluations are made through sample analysis.

Findings- Innovative practices are found to be effective in the banking sector and provide competitive advantages.

Result- Innovation has a decisive and empowering function in the financial sector. The importance of innovation will increase with technological applications.

Keywords: Banking, finance, innovation, technology, Türkiye İş Bankası, information and communication technologies.

JEL Codes: M1, M15.

\section{BANKACILIK ve FINANSAL HIZMETLERDE YENILIKÇiLIK VE TEKNOLOJi UYGULAMALARI: TÜRKIYE iş BANKASI ÖRNEĞi}

\section{ÖZET}

Amaç- Yenilikçi ve teknolojik uygulamalar ile birlikte asıl amaç bilgiye ulaşımı kolaylaştırmak, maliyetleri azaltmak ve müşteri memnuniyetini arttırmak olmuştur. Türkiye İş Bankası da modern dünyada yapmış olduğu çalışmalar ile sektöründe fark yaratmaya çalışan kurumlar arasında yer almıştır. Bu çalışmamızda son dönemde bankacılık ve finans sektöründe yer alan yenilikçi ve teknolojik çalışmalar incelenmektedir ve Türkiye İş Bankası'nın bilim ve iletişim teknolojilerini sektörde nasıl uyguladığı tartışılacaktır.

Yöntem- Çalışma bankacılık sektöründeki inovatif uygulamaları İ̧̧ Bankası örneği aracılığıyla incelemeye dayanmaktadır. Örneklem incelemesi üzerinden değerlendirmeler yapılmaktadır.

Bulgular- İnovasyon uygulamaların bankacılık sektöründe müşteri cezbetmede ve rekabet avantajı sunmada etkili olduğu görülmüştür.

Sonuç- İnovasyon finans sektöründe rekabet gücünü belirleyici ve arttırıcı bir fonksiyona sahiptir. Teknolojik uygulamalarla birlikte inovasyonun önemi daha da artacaktır.

Anahtar Kelimeler: Bankacılık, finans, yenilikçilik, teknoloji, Türkiye İş Bankası, bilgi ve iletişim teknolojileri. JEL Kodu: M1, M15. 


\section{Giriş}

Her sektörde olduğu gibi bankacılık ve finans sektöründe de teknolojik yenilik intiyacı olmazsa olmazlar arasında yer almaktadır. Teknolojik yeniliklere duyulan ihtiyaç gelişmelerin yaşandığı küresel dünyada farklılık yaratmak açısından oldukça önemli görülmektedir. Sunulan hizmetlerin niteliğinde meydana gelebilecek herhangi bir değişiklik farklılaşmaya yol açacaktır ve farklı bir deneyim imkânı sunması açısından müşteriler özelinde oldukça önemli etkiler yaratabilecektir.

Teknolojik gelişmeleri takip edip yatııımlarını bu doğrultuda yapan bankacılık ve finans sektörü aktörleri maliyetlerini azaltabilecek, verimliliği arttırabilecek, kâr oranlarında belirli artışı yakalayabilecektir ve en önemlisi de müşterilerine yönelik farklı bir hizmet deneyimi sunarak pazardaki payını genişletebilecektir. Bu anlamda yapılacak teknolojik bir yatırımın geri dönüşü söz konusu kurum için yatırım bedelinden çok daha büyük bir fayda ile sonuçlanabilecektir. Özellikle veri güvenliği gibi önemli konularda teknolojik yenilikler geliştirebilen kuruluşlar rakiplerine oranla oldukça ön plana çıkabileceklerdir. İnovatif ve teknik açıdan yaratıcı uygulamalar işletmelerin hedef kitleler ile olan iletişimini ve bağını daha da güçlendirmektedir.

Çalışmamızda bankacılık ve finansal hizmetlerin hangi hizmetlerden oluştuğu, bu hizmetleri sunan kuruluşların amaçlarının neler olduğu, finansal hizmetlerin faydalı yönleri ve finansal hizmetlerde teknolojinin rolü örnekler ışığında tartışılmaya çalışılacaktır.

Tüm sektör kuruluşlarında olduğu gibi bankacılık ve finans sektörünün önemli aktörü olan bankalar da teknolojiye önemli yatırımlar yapmak ve kendilerini sürekli olarak geliştirmek durumundadırlar. Türkiye iş̧ Bankası'nda kuruluşundan bu yana teknolojik anlamda attığı adımlar ile bankacılık sektöründe fark yaratarak inovatif açıdan teknolojik altyapısı güçlü bankalar arasında yer almıştır. Çalışmamız bu bankanın dünden bugüne gelişimi göz önüne alınarak teknolojik anlamdaki yatırımları ve yenilikleri özelinde örneklendirilmeye çalışılacaktır.

\section{BANKACILIK VE FINANS SEKTÖRÜNDEKI KURULUŞLARIN AMAÇLARI}

Bankacııık ve finans sektörü bankacılık ağılıklı olmak üzere çeşitli amaçları bulunan geniş bir sektördür. Bu aktörler hizmetleri yerine getirirken belirli amaçlarla hareket etmekte ve amaçlanan sonuçları almak için çeşitli hedefler belirlemektedir. Söz konusu sektörde öncelikle basit ve kullanılabilen uygulamalar geliştirilmeye çalışılmaktadır. Bu sayede daha geniş kesimlere hitap edilebilecektir. Basit ve kullanılabilecek uygulamaların geliştirilmesinin ardından kaliteyi arttırmak hedeflenmektedir. Bütün bunları yaparken teknolojiden olabildiğince faydalanmak bu kuruluşların amaçları arasında yer almaktadır (www.ibm.com).

İnsanların ekonomik varlıkları ile ilgilenen ve bu amaçla faaliyet gösteren kuruluşların güvenlik konusunda da çeşitli çalışmalar yapmak ve hedefler belirlemek durumunda oldukları belirtilebilir. Bu nedenle finansal verilerin güvenli bir şekilde saklanması, sahtecilik ve finansal suçlar (suç gelirlerinin aklanması vb.) ile mücadelede başarı elde etmek ve geleneksel güvenlik mekanizmalarının aşılarak çağa uygun güvenlik önemleri geliştirmek bankacılık ve finans sektöründe faaliyet gösteren kuruluşların temel amaçları arasında yer almaktadır (www.ibm.com). Öte yandan bu durum bir amaç olmaktan ziyade bir görev teşkil etmektedir. Çünkü güvenlik, bankacılık ve finans sektörünün en önemli konuları arasında yer almaktadır.

Güvenlik önlemlerinin yanında önemli olan noktalardan bir diğeri de müşterilere yeni bir deneyim imkânı sunmaktır. Günümüzde karar alma süreçlerini iyileştirerek geleneksel güvenlik mekanizmalarını ötesine geçmeyi başarabilmiş finans kuruluşları, müşteri ilişkilerini yeniden tanımlamak ve müşterilere sunulacak hizmetlere yapay zekâyı da dâhil etmek noktasında önemli adımlar atmak zorundadır. (www.ibm.com).

Bankacııık ve finans kuruluşlarının amaçları sıralanırken bu amaçlarına ulaşmalarını sağlayacak önemli bir faktörden de bahsetmek gerekmektedir. Fintech kuruluşları bankacılık sektöründeki kurumlara yardımcı olmaktadır. Bu kavram yenilikçi iş modeli ile teknolojik araçları bir araya getiren kuruluşları ifade etmektedir. Günümüzde müşteri odaklılı̆ı̆n hizmet sektöründe stratejik açıdan öneminin artmasının ardından bu kavram da ön plana çıkmaktadır. Bu kavram ile birlikte ortaya çıkan kuruluşlar kayıt dışı ekonomiyi kayıt altına almak ve pazar paylarını büyütmek gibi iki önemli işleve sahip olmaktadır. Söz konusu kuruluşlar getirmiş oldukları yenilikler ile büyük kolaylıklar sağlamakta, bankacılık ve finans sektörüne teknik araç ve imkânlar sunma hususunda canlılık kazandırmaktadırlar. Fintech kuruluşlarının sağlamış oldukları servisler arasında, mobil ödemeden yapay zeka destekli portföy yönetimine, kişiden kişiye para transferinden kripto paralara, temassız ödemeden sohbet robotlarına ve sigortacılık teknolojilerinden biyometrik doğrulamaya kadar bir çok servis yer almaktadır. (HALKBANK, 2019).

Bankacılık ve finans sektörü bankacılık ağılıklı olmak üzere çeşitli amaçları bulunan geniş bir sektördür. Bu aktörler hizmetleri yerine getirirken belirli amaçlarla hareket etmekte ve amaçlanan sonuçları almak için çeşitli hedefler belirlemektedir. Söz konusu sektörde öncelikle basit ve kullanılabilen uygulamalar geliştirilmeye çalışılmaktadır. Bu sayede daha geniş kesimlere hitap edilebilecektir. Basit ve kullanılabilecek uygulamaların geliştirilmesinin ardından kaliteyi arttırmak hedeflenmektedir. Bütün bunları yaparken teknolojiden olabildiğince faydalanmak bu kuruluşların amaçları arasında yer almaktadır (www.ibm.com, 24.06.2019).

İnsanların ekonomik varlıkları ile ilgilenen ve bu amaçla faaliyet gösteren kuruluşların güvenlik konusunda da çeşitli çalışmalar yapmak ve hedefler belirlemek durumunda oldukları belirtilebilir. Bu nedenle finansal verilerin güvenli bir şekilde saklanması, sahtecilik ve finansal suçlar (suç gelirlerinin aklanması vb.) ile mücadelede başarı elde etmek ve geleneksel güvenlik mekanizmalarını aşılarak çağa uygun güvenlik önemleri geliştirmek bankacılık ve finans sektöründe faaliyet gösteren kuruluşların temel amaçları arasında yer almaktadır (www.ibm.com, 24.06.2019). Öte yandan bu durum bir amaç olmaktan ziyade bir görev teşkil etmektedir. Çünkü güvenlik, bankacilık ve finans sektörünün en önemli konuları arasında yer almaktadır.

Güvenlik önlemlerinin yanında önemli olan noktalardan bir diğeri de müşterilere yeni bir deneyim imkânı sunmaktır. Günümüzde karar alma süreçlerini iyileştirerek geleneksel güvenlik mekanizmalarının ötesine geçmeyi başarabilmiş finans kuruluşları, müşteri ilişkilerini yeniden tanımlamak ve müşterilere sunulacak hizmetlere yapay zekâyı da dâhil etmek noktasında önemli adımlar atmak zorundadır. (www.ibm.com, 24.06.2019). 
Bankacılık ve finans kuruluşlarının amaçları sıralanırken bu amaçlarına ulaşmalarını sağlayacak önemli bir faktörden de bahsetmek gerekmektedir. Fintech kuruluşları bankacılık sektöründeki kurumlara yardımcı olmaktadır. Bu kavram yenilikçi iş modeli ile teknolojik araçları bir araya getiren kuruluşları ifade etmektedir. Günümüzde müşteri odaklılığın hizmet sektöründe stratejik açıdan öneminin artmasının ardından bu kavram da ön plana çıkmaktadır. Bu kavram ile birlikte ortaya çıkan kuruluşlar kayıt dışı ekonomiyi kayıt altına almak ve pazar paylarını büyütmek gibi iki önemli işleve sahip olmaktadır. Söz konusu kuruluşlar getirmiş oldukları yenilikler ile büyük kolaylıklar sağlamakta, bankacılık ve finans sektörüne teknik araç ve imkânlar sunma hususunda canlılık kazandırmaktadırlar. Fintech kuruluşlarının sağlamış oldukları servisler arasında, mobil ödemeden yapay zeka destekli portföy yönetimine, kişiden kişiye para transferinden kripto paralara, temassız ödemeden sohbet robotlarına ve sigortacılık teknolojilerinden biyometrik doğrulamaya kadar bir çok servis yer almaktadır. (HALKBANK, 2019).

\section{BANKACILIK HIZMETLERININ INOVATIF ROLÜ VE MÜŞTERILERE FAYDALARI}

Günümüzde çok çeşitli bankacılık hizmetlerinden ve finansal hizmetlerden söz etmek mümkündür. Bu hizmetleri temel olarak sigorta ile ilgili hizmetler, bankalar ve diğer hizmet sağlayıcılarının sağlamış olduğu hizmetler şeklinde tasvir etmek mümkündür. Bu hizmetler arasında temel olarak fon kabul etmek, kredi vermek, kredi ve hesap kartları temin etmek, döviz kuru ve türevleri ile ilgili her türlü işlemi yerine getirmek, menkul kıymet çıkarmak ve varlıkları yönetmek sayılabilir. Yine bu anlamda bankacılık ve finans sektörünün belirleyici aktörlerine değinmek gerektiğinde mevduat bankaları, kalkınma ve yatırım bankaları, sigortacılık, sermaye piyasaları, finansal kiralama ve bireysel emeklilik gibi birçok aktörden söz etmek gerekir (Şit ve Şit, 2013: 36). Küreselleşme ile birlikte önemli aktörler haline gelen finans kuruluşları insanların birçok ihtiyacını karşılamak adına farkılaştırılmış ürünler piyasaya sürerek rekabetçi çalışmalarını sürdürmektedir. Bu aktörlerin piyasaya sürdüğü ürünler ile varlık yönetimi konusunda farklı deneyimler ortaya çıkabilmektedir.

Bankacılık ve finans sektörünün temel olarak çeşitlendirilmiş bir hizmet sunum arzına sahip olduğu görülmektedir. Bankalar müşterilerine 7 gün 24 saat hizmet verebilen bir yapıya sahip olmayı hedefleyerek teknolojik altyapıları ile internet bankacılığını rahatlıkla kullanır hale gelmiştir. Bankacılık sektörünün inovatif hizmet sunma arzusu kâr marjını yükseltmeye dayalı rekabetçi baskılardan kaynaklanmaktadır. Küreselleşmenin de etkisiyle bankalar yalnızca ulusal sermayenin değil, yabancı sermayenin de cazibesini çekmeye yönelik girişimlerde bulunmak zorundadırlar. Özetle, bankalar sermaye döngüsünü ve kârlılıklarını arttırmaya yönelik yeni hizmet biçimlerini keşfetmek ve icra etmek gibi bir baskıyla karşı karşıyadır. Sürekli kendilerini yenilemek ve teknolojinin getirdiği imkânları bireysel ve ticari perspektifte müşterilerine anında sunmak durumundadırlar. Örneğin; önceleri yalnızca şube olarak hizmet verebilen bankalar zamanla teknolojinin gelişmesi ile birlikte çeşitli kanalları (mobil aygıtlar, bankamatik, ATM vb.). kullanabilir hale gelmiştir.

Bankacılık sektörünü teknolojik gelişmelerden yararlanmaya ve yenilikçi ürünler geliştirmeye iten bir diğer önemli faktör müşterilerin zaman ve işlem maliyetleri hususlarındaki artan talepleridir. Müşteriler artık daha bilinçli bir hizmet kullanıcısıdır. Daha kısa zamanda bankacılık işlemlerini yapmak istemektedir. Bankanın kendisine sunduğu hizmet karşılığında alınan işlem maliyetlerinden ise kaçınmaktadır. Bu durum zorunlu olarak bankacılık sistemini elektronik ortamda faaliyetlerini yürütmeye zorlamaktadır. Küresel dünyada finansal hizmetler nitelik değiştirmekle beraber faydaları göz ardı edilemeyecek önemli hizmetler şeklinde karşımıza çıkmaktadırlar. Bu hizmetler öncelikli olarak maliyetleri azaltmaktadır. Örneğin; mobil ödeme kanallarına yönlendirmeyi başarabilen bankalar şube içerisindeki personelini faklı pozisyonda değerlendirebilme imkânına kavuşabilecektir. Burada yeni personel alımına ihtiyaç duyulmayacağından basit tabirle işgücünden tasarrruf sağlanarak maliyetler azaltılabilecektir. İnovatif anlamdaki finansal hizmetler piyasalar açısından da olumlu özellikler barındırmakta, piyasaların tam rekabetçi olmasına katkı sağlamakta ve yeni sermaye piyasalarının ortaya çıkmasına yardımcı olmaktadır. Aynı zamanda bu tür hizmetler paranın dolaşım hızını da arttırmaktadır (Kaplan, 1999:1-14). Bu faydalarının yanı sıra inovatif hizmetler rekabeti canlı tutmakta, uluslararası entegrasyonu sağlamakta, sermayenin mobilitesi için yeni fırsatlar sunmakta ve ekonomik büyümeyi olumlu etkilemektedir (Ünal ve Yetiz, 2018: 122-123). Birbiri ile finansal hizmetler konusunda rekabete giren kuruluşlar teknolojik araçlara yatırımı arttırmakta ve bu sayede yeni ürün ve hizmetlerin önünü açarak para ve maliye piyasalarına canlılık kazandırmaktadır. Böylece uluslararası kredi derecelendirme kuruluşları bankaların sermaye yapısını pozitif bir görünüme taşımaktadır ve risk puanlarını azaltmaktadır. Bu hizmetlerden faydalananlar açısından da geniş yelpazeli bir ürün çeşitliliği ortaya çıkmaktadır.

Finansal yeniliklerin artışı hususundaki diğer sebepler arasında enflasyon oranlarındaki artış, faiz ve kur oranlarındaki dalgalanmalar, değişken oranlı borç araçlarının ortaya çıkması, yasal düzenlemelerdeki, vergi kanunlarındaki değişiklikler ve ekonomik büyümenin hızlanmasına duyulan ihtiyaç gibi faktörler sıralanabilir (Kaplan, 1999: 1-14). Örneğin; yasal zorunlu karşılık oranı, faiz oranı sınırı gibi uygulamalar finans kuruluşlarının kendi alanlarında düzenleme yapma ve çeşitli yeniliklere başvurma ihtiyacını arttırmaktadır.

\section{BANKACILIK SEKTÖRÜNDEKI YENILIKÇI UYGULAMALAR}

Bankacılık sektöründe karşımıza çıkan hizmetleri ele aldığımız bu çalışmamızda günümüzdeki bazı yenilikçi uygulamalardan da söz etmekte fayda vardır. Bu durum söz konusu sektörün hizmetlerin sunumu noktasında geldiği son noktayı anlamamız açısından oldukça yararlı olacaktır.

İlk örnek olarak Denizbank tarafından sunulan Fastpay ile Nakitsiz Stadyum Projesi'nden bahsedilebilir. Bu proje ile Ali Sami Yen Spor Kompleksi'nde nakit taşıma ve alışverişte nakit kullanma zorunluluğunun ortadan kaldırılması amaçlanmış olup, müşterilere para kullanmadan alışveriş yapma deneyimi imkânı sunulmuştur (GSK, 2019).

Yine 2018 yılında Akbank, müşterilerinden alınan her 3 imzadan 2'sini ortadan kaldırarak farklı bir deneyim sunmuştur. Bunu yaparken öncelikli olarak mobil uygulamasını geliştiren banka zaman ve kâğıt israfının önüne geçmeyi amaçlamıştır (AKBANK, 2018). Gerçekten de gereksiz birçok imza atmak müşteriler tarafından yorucu olarak görülmesinin yanında oldukça da maliyetli bir yaklaşımdır. Banka açısından da kırtasiyeciliğe yol açmaktadır. 
Bir başka yenilik de Ziraat Bankası'nın geliştirmiş olduğu avuç içi tanıma sistemi ile para çekmek kolaylığıdır. Banka bu uygulama ile banka kartı veya kredi kartı olmadan biyometrik kimlik doğrulama ile para çekmek kolaylığını müşteri memnuniyetine sunmuştur (TCZB, 2019). Burada asıl amaçlanan hızlı ve pratik bir biçimde para çekme kolaylığı sağlamaktır.

Yine Ziraat Bankası'nın uygulamasının bir benzeri de 2016 yılında Yapı Kredi Bankası tarafından kullanıma sunulmuştur. Yapı Kredi göz tarama teknolojisi sayesinde müşterilerine Göz-ID ile mobil bankacılık uygulamaya giriş yapma kolaylığı sunmuştur (YKB, 2016). Burada da işlemlerin hızlı ve pratik şekilde yapılması amaçlanmıştır.

\section{TÜRKIYE IŞ BANKASI'NDAKi INOVASYON GIRIŞ̧iMLERi}

Türkiye İş Bankası Anonim Şirketi (TiBAŞ) bankacılık sektörü söz konusu olduğunda Türkiye ve dünyada karşımıza çıkan sayılı büyük bankalardan biridir. Türkiye İş Bankası finansal yenilikler için önemli bir mali kaynak ayıran ve ayrılan bu kaynak ile sektöre canlılık kazandıran önemli banklalar arasında yer almaktadır. 26 Ağustos 1924'de kurulan bankanın isim babası Hasan Saka'dır. İlk müdürü Celal Bayar olan bankanın 2 şube 37 personel ile kurulduğu anda kuruluş sermayesi olan 1 Milyon Türk Lirası́nın 250 Bin Türk Liralık bölümü Atatürk tarafından karşılanmıştır. Türkiye İş Bankası'nın ortaklık yapısı ise oldukça farklıdır. 31 Mart 2019 itibari ile İş Bankası Munzam Sandık Vakfı'nın ortaklık yapısı içerisindeki payı \%40,47 olurken, Atatürk hisselerinin payı \%28,09 şeklindedir. Halka açık pay ise \%31,44'dür. Kurumun 2019 Mart sonu itibari ile değeri 24.923.114.000 TL'dir. Kurumun 2018 Aralık itibari ile 24 şirketle doğrudan ortaklığı bulunurken kontrol ettiği şirket sayısı ise 110'dur. Kurumun 2018 sonu itibari ile 24.570 çalışanı 1355 yurt içi şubesi, 22 yurt dışı şubesi ve 6560 Bankamatiği bulunmaktadır. 2018 Yılı İtibari ile kurumun aktif büyüklüğü 416,4 milyar TL'dir. Sermaye yeterlilik oranı ise \%16,5'dir (TiBAŞ, 2019).

Kurum finansal teknolojilerin geliştirilmesi amacıyla önemli bir kaynak harcamaktadır. Bu anlamda iki önemli dijital üssü bünyesine katmıştır. 2016 yılında Amerika'da Silikon Vadisi'nde dijital bir üs kuran banka, 2018 yılında da Şangay'da bir inovasyon merkezini bünyesine katmıştır. Bunların yanında yazılım şirketi olan Softtech 1 Şubat 2006'da yerli sermaye ile kurulan ilk yazılım şirketi olarak banka ile birlikte hizmete başlamıştır (TiBAŞ, 2018).

Türkiye İş Bankası'nın finansal yeniliklere sunmuş olduğu katkıyı ve bu anlamda ortaya koyduğu performansı anlayabilmek adına söz konusu bankanın bankacılık sektörüne kazandırmış olduğu ilklere değinmekte fayda vardır. Banka elektronik bankacılığın temellerini atmış ve bankamatiklere isim vererek kullanıcıların hizmetine sunmuştur. İnternetin hayatımızda yer almaya başlaması ile Türkiye İ̧̧ Bankası 1997 yılında Türkiye'nin ilk Internet şubesini kullanıma açmıştır. Kişisel bilgisayarı olmayan müşteriler için ise netmatikler devreye alınmıştır. Burada da müşterilerin hizmetlerden geri kalmasının önüne geçilmeye çalışılmıştır. İnternetin ardından mobil bankacılığın temellerinin de atıldığı dönemde WAP ile bankacılık işlemleri Türkiye'de ilk olarak Türkiye İş Bankası ile telefonlara taşınmıştır. Bunların yanında Türkiye'nin ilk QR kod kullanılan ödeme sistemi olan Parakod'un da Türkiye İş Bankası tarafından müşterilerinin kullanıma sunulduğu görülmektedir (TiBAŞ, 2019).

Türkiye İş Bankası'nın finansal yeniliklere ilkleri ile sağlamış olduğu katkıya değindikten sonra bankanın son dönemde ortaya koyduğu performansa da parantez açmak gerekmektedir. Özellikle son dönemde çağın gereklerine göre hareket eden banka önemli yenilikleri bünyesinde sunmuş ve farklı bir müşteri memnuniyeti deneyimi sunmuştur. 2018 yılında uygulamaya alınan kişisel asistan Maxi ve İstanbul şubesinde karşımıza çıkan Robot Pepper bankanın son dönemdeki iki önemli yeniliği şeklinde sayılabilir. Kişisel asistan Maxi ile birlikte mobil uygulama üzerinden soru-cevap şeklinde interaktif hizmet almak suretiyle faydalanılabilir, Pepper de şubede müşterilere farklı bir hizmet deneyimi sunmaktadır. Banka aynı zamanda kartsız para çekmek için Cep Anahtar uygulamasını devreye sokmuş, elektronik imza uygulaması ile yenilikçi adımlarda bulunmuştur. Banka bireyselmüşterilerine tasarruf alışkanlığı kazandırmak için başlatmış olduğu kumbara uygulamasını bir adım öteye taşıyarak çağımızın gerekleri ile uyumlu dijital kumbara uygulamasını devreye sokmuştur (TiBAŞ , 2019). Görüleceği üzere Türkiye İş Bankası bankacılık ve finans sektöründe ortaya çıkan inovasyon eğilimleri çerçevesinde her dönem farklı ürünler tasarlayıp piyasaya sürerek müşterilerinin kullanımına açmaktadır. Bilgi çağının öngördüğü şekilde kesintisiz ve kaliteli hizmet sunumuyla müşteriler açısından farklılaştırılmış modüler ve proaktif yeniliklerle bankacılık hizmetlerindeki süreçler de teknolojik açıdan dönüşüme maruz kalmıştır.

\section{SONUÇ VE ÖNERILER}

Günümüzde hemen her sektörde teknolojik uygulamaların ağırlığından söz edilebilir. Mal, sermaye ve insanların olabildiğince hareketli olduğu bu dönemde teknolojik gelişmelerin ışı̆̆ında yenilikçi uygulamalar geliştirmek ve bu sayede piyasa aktörleri arasında belirgin bir fark yaratabilmek her sektör için başat hedefler arasında yer almaktadır. Bankacılık sektörü de küreselleşmenin ve dijitalleşmenin getirdiği inovatif değişikliklere maruz kalmaktadır. Bankalar ve diğer çeşitli finansal kuruluşların sunmuş olduğu hizmetler temelde aynı amaca hizmet etse de hizmet sunumu esnasında farklılaşmalar meydana gelmektedir. Finansal hizmetlerin insanlara sunmuş olduğu faydanın arttırılması için sunumu sağlanan hizmetlerin kalitesi büyük önem taşımaktadır. Bu noltada teknolojik yatırımların ve araştırma geliştirme faaliyetlerinin çeşitlendirilmesi sürekli öğrenme ve gelime temelinde geleceğe dair somut stratejik hedef ve amaçların bir misyon temelinde tanımlanması gerekmektedir. Kurumsal bazda teknolojik performansın arttırılmasının müşteri memnuniyetini teşvik edeceği düşünüldüğünde uzun vadeli bir vizyonun belirlenmesi gelecekte atılacak adımları belirleyecektir. Teknolojik olarak yatırımlarını önceliklendiren kuruluşların finansal piyasalarda kredibilitesinin artacağı ve ekonomik pozisyon bakımından sermaye yapılarını sabit ve olumlu yönde geliştirebilecekleri açıktır.

Türkiye İş Bankası yapmış olduğu teknolojik yatırım ve tarihsel birikimi le Türkiye ve Dünya'da fark yaratan bankalar arasında yer almaktadır. Özellikle kurmuş olduğu iki teknoloji üssü ile bu alandaki yatırımlarını arttırmış ve gelecek adına önemli adımlar atmıştır. Türkiye İş Bankası'nın atmış olduğu bu adımların diğer sektör temsilcileri tarafından da atılması, teknolojik yatırımların arttırılması gerekmektedir. Teknolojik yatırımların arttığı rekabet dolu bir bankacılık ve finans sektörü, kaliteli hizmet sunumu ve müşteri memnuniyetinde yeni deneyimleri de beraberinde getirecektir. Ülke ekonomisinin gelişebilmesi ve istihdam yaratabilme bakımından kurumsal düzeyde inovasyon kabiliyeti ayrı bir değer taşımaktadır. Bu artı değer Türkiye gibi yükselen piyasalara yabancı sermaye çekebilmek açısından oldukça önemlidir. Kurumsal açıdan değişimi takip eden ve dünyadaki trendleri izleyen finansal kurumlar inovatif bakımdan belirsizlik ve riskleri minimuma çekerek fiyatlama davranışlarında da rasyonelliği temin ederler. 


\section{KAYNAKÇA}

AKBANK (2018). Akbank Türk Anonim Şirketi, https://www.akbank.com/tr-tr/hizmetler/Sayfalar/akbank-donusum-projesi.aspx, (ET: 23.06.2019).

GSK (2019). Galatasaray Spor Kulübü, https://www.galatasaray.org/haber/kulup/galatasaray-ve-denizbank-fastpay-ile-turkiye-nin-ilknakitsiz-stadyum-uygulamasini-baslatti/43726, (ET: 23.06.2019).

HALKBANK (2019). Türkiye Halk Bankası Anonim Şirketi, https://www.halkbankkobigelisim.com.tr/Resources/Sites/57/images/Files/4HALKBANK KOBI GELISIM-Fintech\%20Nedir Bora Erkmen.pdf , (ET: 23.06.2019).

IBM, https://www.ibm.com/tr-tr/industries/banking-financial-markets, (ET: 23.06.2019).

Kaplan, C. (1999). Finansal Yenilikler ve Piyasalar Üzerine Etkileri: Türkiye Örneği. Türkiye Cumhuriyeti Merkez Bankası Araştırma Genel Müdürlüğü, Tartışma Tebliği No: 9910, s. 1-34.

TCZB (2019). Türkiye Cumhuriyeti Ziraat Bankası Anonim Şirketi, https://www.ziraatbank.com.tr/tr/bankamiz/basin-odasi/ziraattenyenilikler/atm-avuc-ici-tanima-sistemi, (ET: 23.06.2019).

TiBAŞ (2018). Türkiye iş Bankası Anonim Şirketi, https://www.isbank.com.tr/TR/hakkimizda/haberler-vemedya/haberler/Sayfalar/haberler.aspx?4DDCBC12-B456-4049-8BDA-FB3415CAE7E1idCol=4328 , (ET: 23.06.2019).

TiBAŞ (2019). Türkiye Iş Bankası Anonim Şirketi, https://www.isbank.com.tr/TR/hakkimizda/bizi-taniyin/tarihimiz/o-gunlerdenbugunlere/Sayfalar/o-gunlerden-bugunlere.aspx , (ET: 23.06.2019).

TiBAŞ (2019). Türkiye İ̧̧ Bankası Anonim Şirketi, https://www.isbank.com.tr/TR/hakkimizda/yatirimci-iliskileri/kurumsal-bilgiler/ortaklikyapisi/Sayfalar/ortaklik-yapisi.aspx, (ET: 23.06.2019).

TiBAŞ (2019). Türkiye İ̧̧ Bankası Anonim Şirketi, https://www.isbank.com.tr/TR/hakkimizda/yatirimci-iliskileri/finansalbilgiler/Documents/FaaliyetRaporlari/FaaliyetRaporu2018.pdf, (ET: 23.06.2019).

TiBAŞ (2019). Türkiye İş Bankası Anonim Şirketi, https://www.isbank.com.tr/TR/hakkimizda/bizitaniyin/tarihimiz/ilklerimiz/Sayfalar/ilklerimiz.aspx, (ET: 23.06.2019).

TiBAŞ (2019). Türkiye İş Bankası Anonim Şirketi, https://www.isbank.com.tr/TR/hakkimizda/bizitaniyin/istiraklerimiz/Sayfalar/istiraklerimiz.aspx, (ET: 23.06.2019).

Ünal, A. E., Yetiz, F. (2018). Finansal Yeniliklerin Gelişimi ve Türk Bankacılık Sektörüne Etkileri. Kastamonu Üniversitesi, İktisadi ve İdari Bilimler Fakültesi Dergisi, 20(4), s. 117-135.

Şit, A., Şit, M. (2013). Türkiye'de Finansal Hizmetler Sektörünün Gelişimi: Finansal Kiralama Sektörü Örneği. Dicle Üniversitesi, İktisadi ve İdari Bilimler Fakültesi Dergisi, 2(5), s. 35-47.

YKB (2016). Yapı ve Kredi Bankası Anonim Şirketi, https://www.yapikredi.com.tr/sinirsiz-bankacilik/mobil-bankacilik/goz-id, (ET: 23.06.2019). 